\title{
Share and share alike: encouraging the reuse of academic resources through the Scottish electronic Staff Development Library.
}

Lorna M. Campbell,* Allison Littlejohn* and Charles Duncan***

*Centre for Academic Practice, University of Strathclyde

**Department of Meteorology, University of Edinburgh

email:Imc@strath.ac.uk

This paper reports on the findings of a consultancy procedure conducted within the Scottish Higher Education staff development community and focusing on the reuse and sharing of communications and information technology. resources for teaching and learning. While this consultancy was conducted primarily to inform the development of the Scottish electronic Staff Development Library (SeSDL), its findings will be of: relevance to colleagues working in the fields of staff development and C\&IT and all those involved in the creation of shared teaching and learning resources. The consultancy identified general staff development demands, specific pedagogical requirements and concerns relating to the provision, reuse and sharing of staff development resources. The SeSDL Project will attempt to address these demands through the development of a Web-based resource centre, which will facilitate the reuse and sharing of high-quality staff development resources. Library materials are stored in the form of granules which are branded with IMS compatible metadata and which are classified using a controlled educational taxonomy. Staff developers will be able to assemble these granular components to build customized lessons tailored to meet the needs of their own departments and institutions.

\section{Introduction}

The Scottish electronic Staff Development Library (http://www.sesdl.scotcit.ac.uk) is an ongoing collaborative project involving the Universities of Edinburgh, Paisley and Strathclyde which has been funded by SHEFC as part of their current ScotCIT Programme (http://www.scotcit.ac.uk). This project is being developed in response to the increasing demand for flexible, high-quality staff development materials. Following the 
creation of the Institute for Learning and Teaching (http://www.ilt.ac.uk) and the impact of the Investors in People (http://www.iipuk:co.uk) programme, institutions are increasingly appreciating the necessity of providing their staff with opportunities for continuous professional development. However, producing high-quality staff development materials tailored to address an extensive range of educational requirements and delivering these materials efficiently and effectively to a wide body of staff can be challenging, costly and time-consuming. In addition, this responsibility may frequently be distributed across several departments in any given institution. In order to cater for such diverse and dynamic learner requirements, staff developers are increasingly turning towards communication and information technologies as an efficient platform for supporting the delivery of flexible learning resources (Littlejohn and Cameron, 1999). However, to create such materials, staff developers must possess not only a thorough appreciation of pedagogical principles but also a detailed understanding of technical procedures. Access to pedagogically sound case studics and best-practice exemplars is also helpful to allow staff developers to illustrate the process of creating learning materials from theoretical inception through design, implementation and evaluation. The expertise and resources required to create highquality educational materials of this kind are not always available in a single staff development unit.

One possible solution to this problem is for staff developers to share a common pool of online resources. However, there are many barriers that have traditionally prevented academic staff from sharing their materials. These barriers range from technical problems such as the use of incompatible systems and file formats to deep-seated concerns over the quality assurance of externally produced materials and the loss of intellectual property rights. In addition, as institutions are increasingly being encouraged to commercialize, it is understandable that academics might be unwilling to share materials freely, especially if they carry accreditation and have significant economic potential.

\section{The Electronic Library}

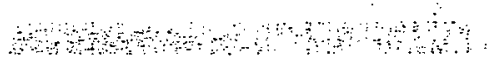

The Scottish electronic Staff Development Library (SeSDL) is attempting to address these issues through the creation of a Web-based resource centre designed to encourage the sharing and reuse of staff development materials. The electronic library is a repository of reuseable resources contributed by the Scottish staff development user community and held on a central server as opposed to an information gateway, defined by Belcher as 'an online service that provides links to numerous other sites or documents on the Internet' (Belcher, Place and Conole, 2000). The resource centre primarily hosts materials that focus on the use of C\&IT for teaching and learning, which can be delivered via the Web and which can accommodate a number of different flexible approaches to staff development.

\section{Granules and metadata}

Library materials are stored in the form of 'granules', the smallest logical components into which educational materials can be divided (Duncan, Bennett, Bond, Douglas, Black, Barrera, Deruy and Gonduouin, forthcoming). A granule may be a single Web page, a linked series of Web pages, an online assessment, an audio file, a video clip or even a single image or diagram. The level of granularity is defined by the content author when each resource is uploaded to the library. Each granule is accompanied by a set of IMS metadata 
(Anderson and Wason, 2000) that is both searchable and extensible. This metadata not only includes core fields such as author, date, version, format, etc., but also encompasses each granule's educational associations and conditions and history of use.

\section{Library interface}

Within the library interface staff developers can assemble these granular components as they require, in order to build customized lessons tailored to meet the training needs of their own departments and institutions. Granular materials can also be added to the library by staff developers who see the potential for their reuse at a national and even international level. In this way the considerable effort involved in producing high-quality educational materials may be shared among many institutions. The resulting lessons will be accessible directly through the electronic library or can be exported as standard IMS content packages (Anderson and McKell, 2000) which can be imported into any other IMS-supporting virtual learning environment. The Scottish electronic Staff Development Library is being developed from a tried and tested Web-based framework which has been created and refined by the EuroMET (http://www.euromet.met.ed.ac.uk) project and the National Learning Network for Remote Sensing (http:/lwww.nln.met.ed.ac.uk)

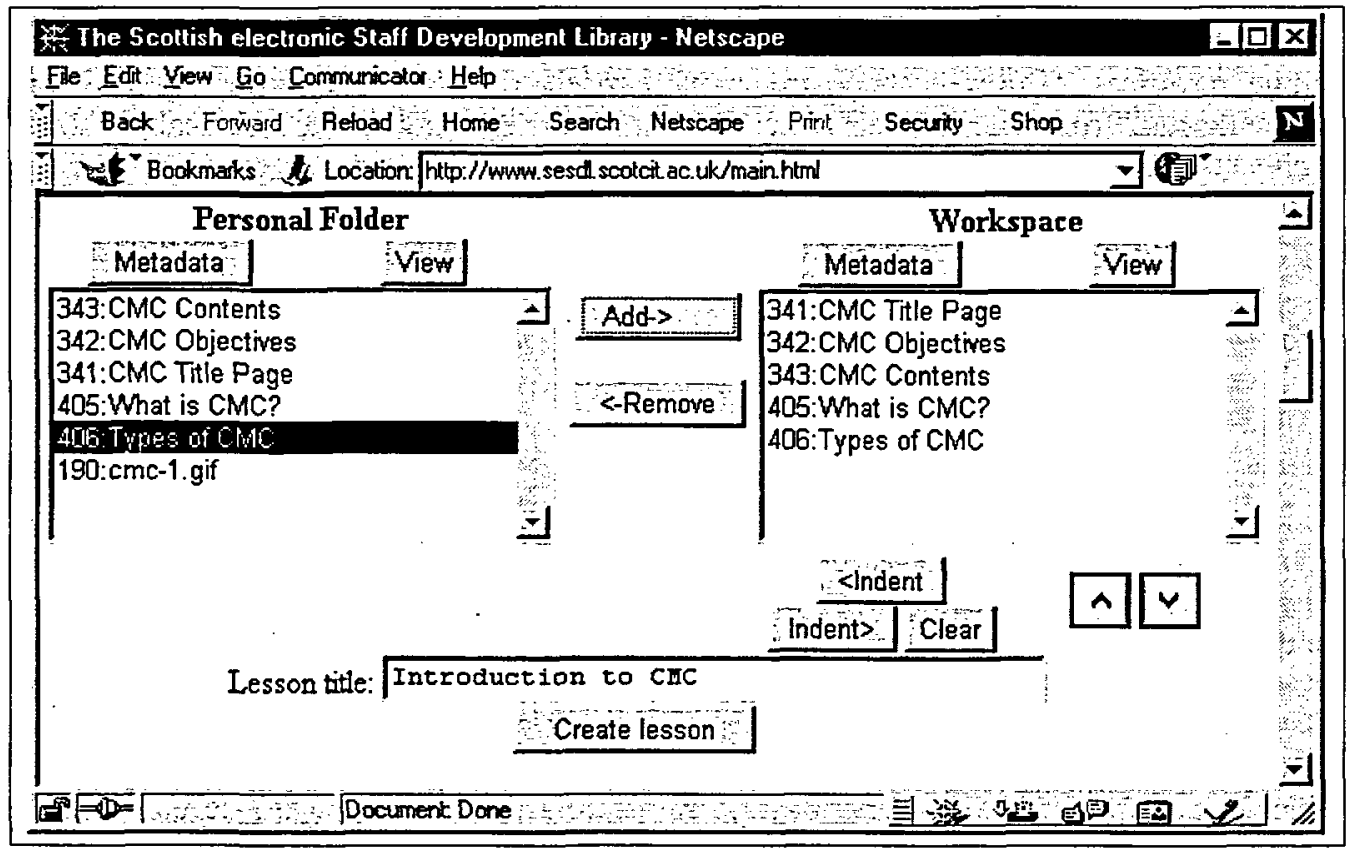

Figure 1: Lesson builder interface

\section{Consultancy procedure}

In order to tailor the development of the electronic library to meet the needs and requirements of the Scottish staff development community, the project conducted a formative consultancy procedure focusing on the use of communications and information technology 
(C\&IT) for teaching and learning (http://www.sesdl.scotcit.acuk/report.html). Amongst wideranging aims this consultancy sought to identify gaps in the current provision of C\&IT-related staff development resources, to record attitudes towards the sharing and reuse of materials, to identify factors which would encourage or discourage staff from contributing resources to the library and generally prioritize users' requirements. The consultancy procedure comprised two workshops, a follow-up video-conference open to all Scottish HEIs, discussions and hands-on trials of a pre-prototype user interface. Data were gathered through a series of group discussions and questionnaires. The questionnaires recorded the confidential responses of individual staff developers for later analysis, while the discussions gave participants the opportunity to explore further some of the specific issues that arose.

The invitation to participate in the consultancy was extended to staff developers at twentyone Scottish HEIs. Rather than canvassing the Scottish staff development community as a whole, the project targeted the smaller subset of colleagues who are already supporting the use of C\&IT for teaching and learning. These are the staff developers who have the potential to contribute resources to the library and who will be offered the opportunity to become early adopters of the prototype system. SeSDL were successful in engaging a high percentage of this target audience to participate in the consultancy procedure. A total of thirty-two staff developers currently supporting the use of C\&IT for teaching and learning contributed to the consultancy workshops and follow up video-conference. Many of the staff who participated are also involved with other SHEFC-funded C\&IT projects. SeSDL has continued to liaise closely and foster links with these projects in order to maximize the outputs of the electronic library project and ScotCIT programme as a whole.

Staff developers with little or no experience of using C\&IT for teaching and learning were not invited to participate in this initial consultancy procedure; their feedback may, however, be sought at a later date as learners using the library under the guidance of their carly adopter colleagues. Ultimately it is hoped that those staff developers who currently focus more on theory and pedagogy than on the use of communication and information technology will eventually go on to contribute their own considerable resource base of knowledge and learning to the library. This synergy between pedagogical and technological expertise will be crucial if the electronic library is to fulfil its true potential and become widely adopted throughout the staff development community.

\section{Methodology}

During the initial stage of the consultation a total of twenty-six participants attended one of two workshops which explored the potential of online learning resources for staff devclopment. These workshops conducted an assessment of the varying institutional requirements of staff developers through a series of questionnaires and group discussions. The first questionnaire focused on the current availability of materials, modes of teaching, factors which would encourage or inhibit use of the library, institutional implementation, using externally produced resources, copyright, intellectual property rights (IPR), quality assurance and contributing and sharing materials. The second questionnaire recorded confidence in using the Internet for teaching and learning, current use of C\&IT tools, practical aspects of using the library and the level of support required. A brief preliminary analysis of these questionnaires was posted to the SeSDL Website shortly after the final workshop along with a 'wish list' of requirements distilled from the many suggestions put 
forward by the workshop participants. One month later SeSDL hosted a follow up videoconference that was attended by seventeen staff from eleven institutions. The results of the primary workshop analysis and the 'wish list' were presented to the participants who then had the opportunity to prioritize their requirements further. A first draft of the electronic library's 'Conditions of Use' agreement, formulated following in-depth discussions at both workshops, was also presented at the video-conference.

\section{Analysis}

Given the ever-widening remit of staff developers and the range of pedagogies and learning styles they must accommodate, it is perhaps unsurprising that the consultancy procedure resulted in a wide diversity of user requirements. However the video-conference which followed the initial consultancy workshops allowed staff developers to prioritize the requirements derived from the workshop questionnaires and discussions. As a result it has been possible to summarize the primary outcomes of the consultancy procedure as follows.

\section{Using an online library}

The majority of staff developers who participated in the consultancy procedure agreed that an online library of staff development materials would be a valuable addition to the resources currently available to them. The staff developers questioned responded positively to the development of the online library and saw no major institutional barriers that would prevent them from accessing such a resource and integrating it into their current curriculum. However, it is worth reiterating that the majority of staff developers who participated in this consultancy procedure were already familiar: with using C\&IT for teaching and learning. While these staff appear enthusiastic about the potential of the electronic library it is possible that other staff developers and learners who are less familiar with the technology may require some encouragement to integrate such a resource with their current framework of teaching and learning.

\section{Pedagogical requirements}

Among the wide range of user requirements identified through the consultancy procedure, one of the most significant is the necessity for the online resource base to be able to accommodate a wide range of pedagogies, both in terms of content and delivery. All consultancy participants clearly prioritized the demand for materials focusing on process and pedagogy, and for practical case studies that demonstrate sound pedagogy and illustrate how to embed C\&IT within the staff development curriculum. Guidelines on legal and ethical issues relating to IPR, equality and accessibility were also identified as a high priority. Consultancy participants also indicated that the library must have the ability to deliver materials in such a way that they can accommodate the varied pedagogies and modes of teaching employed by staff developers to achieve their wide-ranging educational goals and to meet the varied needs of their learners. The granular nature of the library content will help to maximize the potential of the available materials to meet these diverse pedagogical requirements. As materials will be stored in the form of granules; rather than as complete courses, staff developers have the ability to tailor these resources to create courses that meet their own specific requirements and those of their learners. Each course and its mode of delivery will be unique. 


\section{Using externally produced materials}

Participants responded extremely positively to the prospect of being able to access resources produced out-with their own institutions. However, this enthusiasm was qualified by the condition that most staff developers would only consider using externally produced materials if they were quality-controlled, peer-reviewed and of clearly identifiable authorship and provenance. It is possible that this positive attitude towards externally produced materials partially results from the success of initiatives such as TALiSMAN (htt!://www.talisman.hw.ac.uk/) and Netskills (http://www.netskills.ac.uk/), which have produced a range of high-quality resources that have been widely adopted throughout the staff development community. The electronic library will address many of the concerns relating to the quality and provenance of externally produced materials by ensuring that all granules are accompanied by a comprehensive set of metadata. This metadata includes, amongst many other fields, the author's name and institution, the date the granule was authored and the degree to which it can be reused. While granules submitted to the library will not undergo a formal review procedure, a dynamically generated history of use effectively results in a continuous peer-review process. In addition to recording automatically who has used each granule, the library will also allow users to search for widely used granules on any given topic.

\section{Shared resources, IPR, copyright and conditions of use}

While the staff questioned during the consultancy procedure were clearly keen to access resources produced by the wider staff development community, they appeared to be rather more reticent about committing their own materials to a shared resource base. Predictably, loss of copyright and intellectual property rights were cited as two of the most significant concerns relating to the sharing of resources. Many of these concerns can be dealt with by the detailed information contained in the metadata that accompanies all granules submitted to the library. As outlined above, this metadata includes a full suite of information recording the granule's author and provenance. In addition SeSDL guarantees that once a granule has been uploaded to the library it will not be altered or further subdivided. If a user wishes to edit or amend an existing granule a new instance of that granule will be created along with a new set of metadata which records the granule's original author and subsequent editors. While the library retains copyright of this metadata, copyright of the granules themselves resides with the original authors and their institutions.

In addition to copyright and IPR concerns, financial factors were also of consideration, particularly in relation to the use of shared resources for potentially profitable consultancy contracts. Many of the staff developers questioned initially indicated that they would be less willing to share materials if there was a possibility that other staff developers would be able to use these materials for profit.

Another problematic issue raised was that of reciprocity. Some consultancy participants, particularly those from larger institutions; felt that while they might be in a position to contribute material to the library they would have little to gain if other institutions did not submit corresponding resources. This led to the suggestion that entry to the library user group or community should be dictated by an institution's willingness or ability to contribute materials. Although the adoption of such a policy may have encouraged certain 
groups of users to contribute to the library, SeSDL decided against this policy, primarily because it would disadvantage institutions with a smaller pool of staff developers and resources. These are precisely the users to whom the library should be of greatest value. In order to encourage colleagues and early adopters to support and contribute to the electronic library, SeSDL will initially populate the resource base with a range of highquality granular learning resources focusing on the use of learning technologies. SeSDL will also provide access to resources produced by some of the other current ScotCIT projects in order to encourage the sharing of resources between institutions.

Many of the concerns voiced by the staff developers who participated in the consultancy procedure may result from a lack of collaboration between HEIs; there has previously been little encouragement or incentive to share academic resources between institutions. The SeSDL project hopes to overcome these reservations by fostering a collaborative ethos and by producing a resources base that will encourage and facilitate the sharing and reuse of academic resources in a controlled educational environment. As the Scottish electronic Staff Development Library is a SHEFC-funded initiative, the SeSDL team agreed that materials produced directly through the project should be made freely available to all SHEFC-funded institutions. Following lengthy discussions with the consultancy participants, it was also decided that authors should only submit material to the library if they agreed that the materials could be used by staff in any SHEFC-funded institution in the normal course of their business, with the normal course of a university's business being taken to include research and consultancy as well as teaching.

In order to clarify these complex issues SeSDL has drawn up a 'Conditions of Use' agreement which all library contributors and users must acknowledge and accept. This agreement states that the copyright of each granule resides with the author, or author's institution, and that it is the responsibility of the author to seek permission from coauthors or third party authors before uploading material to the library. Copyright of the metadata resides with the library itself and while this metadata will be made freely available, the library also guarantees that the granules themselves will always be accompanied by their associated metadata. All contributors must agree that their materials can be used freely by all Scottish higher education institutions in the normal course of their business, which is taken to include research and consultancy. However the right to dictate the degree to which granules can be reused out-with the Scottish higher education community lies with the author. An additional clause allows contributors the option of extending this free access to all UK HEIs. However, anyone out-with the UK HEI community wishing to use these resources is required to contact the author directly to request permission and agree conditions of use and any associated costs.

The Conditions of Use agreement represents SeSDL's best efforts to protect library contributors' intellectual property rights. All contributors must agree to these conditions of use before uploading their resources to the electronic library. The SeSDL project is aware that little can be done to prevent individuals from maliciously breaching copyright within the electronic library, but the potential danger of plagiarism and breach of copyright is not confined solely to shared electronic resources. As SeSDL is committed to facilitating the sharing of educational resources and fostering collaboration between institutions, it will accept the Conditions of Use agreement and all materials submitted to the library in good faith and would urge users and contributors to do likewise. 
The electronic library is still under development and the Conditions of Use have only recently been fully implemented so it is too early to state with confidence whether this agreement will encourage or discourage colleagues from contributing their valuable resources to the library. However, initial reactions to an early draft of the SeSDL Conditions of Use have been promising, the agreement met with widespread approval within the staff development community and beyond and it has already been adopted by other C\&IT projects. While the final agreement may not find multilateral agreement across all HEIs, SeSDL believe that if the library is successfully to promote an ethos of sharing and is to facilitate the reuse of resources then those resources should be made available to all Scottish HE staff on an equal basis.

\section{A library needs a librarian}

While the consultancy participants predominantly responded that they were confident in using online resources for teaching and learning, they also indicated that the library would have to provide a considerable degree of support if it is to be widely adopted throughout the staff development community. Some of the support requested relates to technical procedures such as converting, granularizing and uploading materials and navigating the user interface. However, many participants also indicated that to fulfil its potential the library must also provide users with guidance on classifying uploaded materials, accessing existing materials and selecting those that are most appropriate for their learners' requirements. This was summed up by one staff developer's insistence that 'a library needs a librarian' - a guide to help users locate appropriate resources.

While a librarian would be a valuable addition to the electronic library, unfortunately there are insufficient resources available to support the provision of such a service throughout the funded phase of the project and beyond. Supporting projects beyond their initial phase of funding is a perennial problem and one of which SeSDL is well aware. One of the clearly stated aims of the SeSDL project is that ownership and control of the electronic library should be transferred progressively to the staff development community as a whole in an attempt to overcome the need for continued technical support (Duncan, Maclaren, Finnigan, Gordon and Littlejohn, 1999). In order to do this the library has been designed in such a way as to place as much functionality as possible in the hands of the users. All library users must have the ability to upload easily, classify, locate, evaluate and implement resources with minimal support.

The IMS metadata that accompanies all library granules will be invaluable in helping users to locate and access resources. The library upload tool, which will allow contributors to add granules to the library, has been designed to automate much of the process of adding mctadata to the resources. Library users can then search for resources using either a simple search tool that searches through all metadata fields or an advanced search tool that allows users to search through selected metadata fields.

Metadata is invaluable for describing and locating resources, but SeSDL also believed that the library should enable authors to classify their resources and, in addition, help users to contextualize the academic content of each granule. For this reason SeSDL decided that the library's functionality would be improved by the development of a standard educational taxonomy, an ordered classification system where information is grouped 
according to presumed natural relationships. The taxonomy will provide contributors with a framework to classify their materials and, in addition, will help users to contexualize library resources through the creation of a browse tree, which can group materials together by common themes and content. Hopefully such a taxonomy will fulfil some of the functions of a librarian.

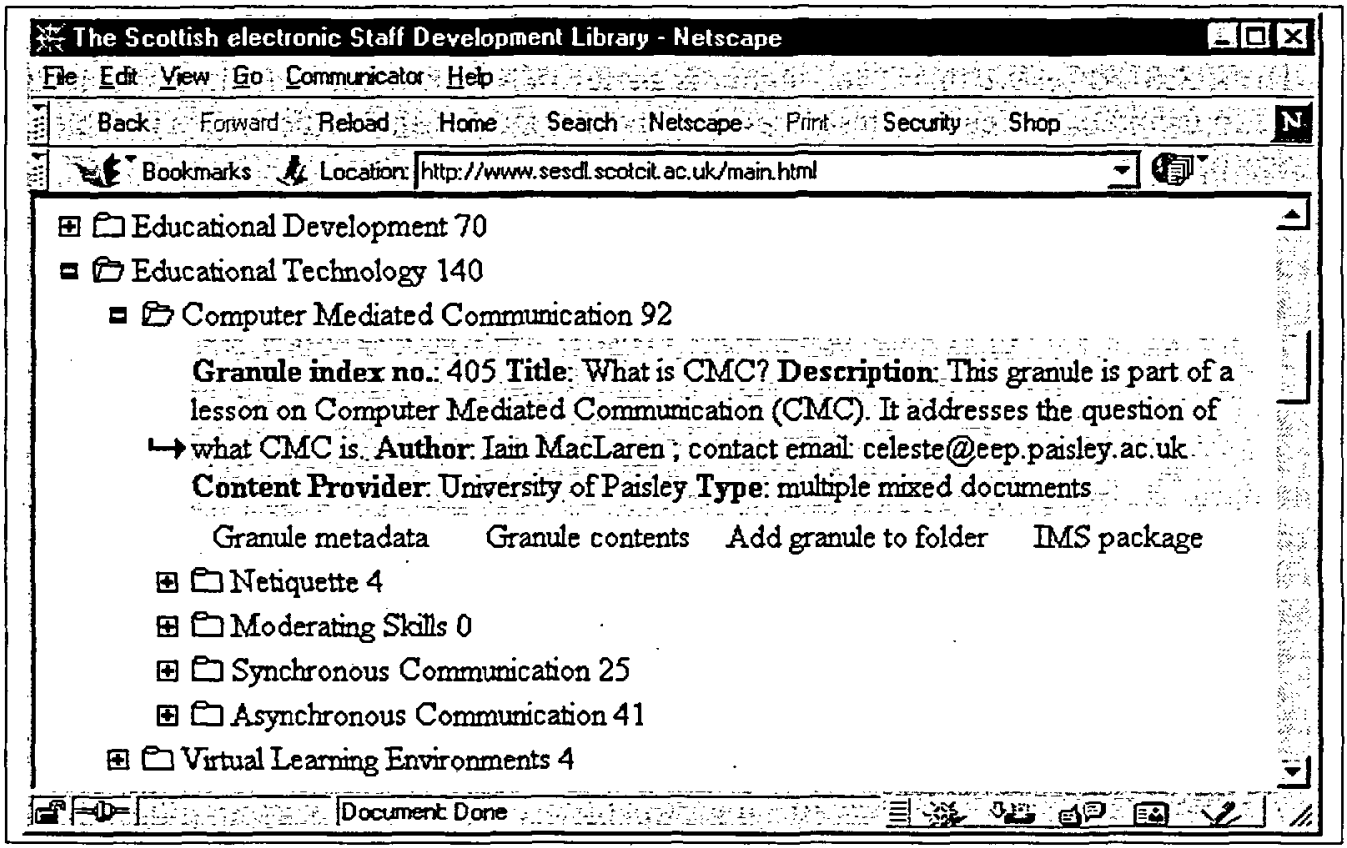

Figure 2: Section of the SeSDL browse tree and taxonomy

SeSDL liaised closely with other C\&IT projects and specialists from the field of information science in order to establish a standard taxonomy covering the use of C\&IT for teaching and learning. Existing educational thesauri such as the Thesaurus of ERIC Descriptors (http://www.csal.co.uk/helpV3/ericthes.html) and the European Education Thesaurus (http://www.eurydice.org/TeeForm/frameset_en.htm) were considered but subsequently rejected. as their terminology does not match UK English usage in higher education closely enough. The TLTP3 Database of Case Studies Vocabulary (http://www.hcu.ox.ac.uk/vocabulary/) was also investigated. Although this vocabulary did not have sufficient scope to meet the electronic library's requirements it proved to be a valuable starting-point for the development of the SeSDL taxonomy.

SeSDL has now developed an educational taxonomy covering the fields of educational development, educational technology, academic management, resource types and subjects (http://www.sesdl.scotcit.ac.uk/taxonomy/). A full analysis of the development and implementation of the SeSDL taxonomy will be presented in future publications. This taxonomy has attempted to encompass vocabularies which describe not only the use of C\&IT for teaching and learning but also more generic educational practices and 
pedagogical principles in a language that is comprehensible to all staff developers. Within the library the taxonomy allows users to classify their resources at the point of upload and in addition has facilitated the creation of a hierarchical browse tree. The wider aim of the SeSDL taxonomy is to help make academic materials as accessible and interoperable as possible. If the taxonomy is successful in fulfilling these functions and if it idopted as a standard by other related C\&IT projects then it will increasingly enable users to access materials from a wide range of sources.

\section{Conclusion}

The SeSDL consultancy procedure has clearly indicated that while staff developers are enthusiastic about the potential of accessing a shared repository of common resources they are still perhaps reticent about the prospect of sharing their own materials freely between institutions. This contradictory position perhaps results from the current dichotomy whereby institutions are increasingly expected to collaborate to receive research funding but, at the same time, are encouraged to commercialize and to draw in external funding through research, consultancy and the exploitation of commercial potential. However, SeSDL believe that if staff developers are to meet the changing needs of their learners and to fulfil efficiently and effectively the increasing demand for high-quality staff development materials they should seriously consider not only reusing but also sharing their resources. The primary aim of the SeSDL project is to construct a resource base of interoperable staff development materials that will facilitate such sharing. As library materials are stored in the form of granules, rather than in the form of complete courses, individual institutions have the ability to tailor these resources to create courses that meet their own specific requirements and those of their learners. As each course and its mode of delivery will be unique, it remains the responsibility of each institution to seek accreditation for these courses, as and when they see fit. By sharing granular materials through the electronic library, not only is the profile of the authors and their institutions raised, but all staff developers have access to a wider pool of resources. As well as sharing resources library users also have the opportunity to share their real teaching and learning experiences.

It is too early to predict with confidence how successful the electronic library project will be in achieving these complex aims and objectives. However, SeSDL believe that the creation of an online environment where materials can be shared and reused in a standard format and on an equal basis is an important first step towards fostering the development of a collaborative ethos and facilitating the establishment of a wide pool of interoperable educational resources. Through this consultancy procedure the Scottish electronic Staff Development Library will maximize the potential of this resource base to address the requirements of all staff developers and meet the needs of learners within the Scottish higher education community and beyond.

\section{Acknowledgements}

SeSDL would like to thank all those who participated in the consultancy procedure and to acknowledge their valuable contribution to the project.

The SeSDL Project team are: Dr Charles Duncan and Eddie Boyle, University of Edinburgh, Dr Iain MacLaren, Tom Finnigan and Celeste McLaughlin, University of 
Paisley and Prof. George Gordon, Dr Allison Littlejohn, Lorna M. Campbell and Sarah Currier, University of Strathclyde.

\section{References}

Anderson, T. and McKell, M. (2000), 'IMS content packaging information model', Version 1.1, Public Draft Specification, http://www.imsproject.org/content/packaging/ cpinfoll.html.

Anderson, T. and Wason, T. (2000), 'IMS learning resources meta-data information model', Version 1.1, Final Specification, http://www.imsproject.org/metadatal mdinfov1p1.html.

Belcher, M., Place, E. and Conole, G. (2000), 'Quality assurance in subject gateways', Quality Assurance in Education, 8 (1), 38-47.

Campbell, L. M. (2000), 'The SeSDL staff development consultancy report', http://www.sesdl.scotcit.ac.uk/report.html.

Duncan, C., Bennett, S., Bond, S., Douglas, P., Black, R., Barrera, C., Deruy, C. and Gonduouin, D. (forthcoming), 'Modularity and granularity: essential steps towards reusable educational objects', British Journal of Educational Technology.

Duncan, C., MacLaren, I., Finnigan, T., Gordon, G., and Littlejohn, A. (1999) 'Scottish Electronic Staff Development Library (SESDL)', Proposal to SHEFC in response to Circular Letter 26/99 Communications and Information Technology Programme, Public version, http://www.sesdl.scotcit.ac.uk.

EuroMet: European Meteorological Education and Training, http://www.euromet.met. edacukl.

European Education Thesaurus, http://www.eurydice.org/TeeForm/frameset_en.htm.

Littlejohn, A. and Cameron, S. (1999), 'Supporting strategic cultural change: the Strathclyde Learning Technology Initiative', $A L T-J, 7$ (3), 64-74. 